\title{
HistoryIcó - Um Aplicativo como Instrumento de Auxílio à Educação Patrimonial
}

\author{
Tulio Vidal Rolim ${ }^{1}$, Francisca Talitha Fernandes Alencar ${ }^{2}$, \\ Maria Raquel Gomes da Costa ${ }^{3}$ \\ ${ }^{1}$ Universidade Federal do Ceará (UFC), Fortaleza - CE - Brasil \\ ${ }^{1}$ Faculdade Vale do Salgado (FVS), Icó - CE - Brasil \\ \{tulio.xcrtf, alencartalitha, raquelacop\}@gmail.com
}

\begin{abstract}
Continuously the forms of the past are being replaced by others of the present, at the same time leaving aside their due importance. The objective of this study is to validate an application as an aid to heritage education. For that, the HistoryIco application was used in the discipline of the history of the municipality in a school in Icó-Ceará with 32 students. The results showed that HistoryIco has brought a positive experience in learning content related to the heritage, traditions and beliefs of the city. Finally, the use of an application as an aid instrument has proven to be a viable alternative for stimulating historical learning and heritage education.
\end{abstract}

Resumo. Continuamente as formas do passado estão sendo substituídas por outras do presente, ao mesmo tempo deixando de lado a sua devida importância. $O$ objetivo deste trabalho consiste em validar um aplicativo como instrumento de auxílio à educação patrimonial. Para tal, o aplicativo HistoryIcó foi utilizado na disciplina de história do município em uma escola de Icó-Ceará com uma amostra de 32 alunos. Os resultados mostraram que o HistoryIcó trouxe uma experiência positiva no que tange à aprendizagem de conteúdos relacionados ao patrimônio, tradições e crenças da cidade. Por fim, o uso de um aplicativo como instrumento de auxílio demonstrou ser uma alternativa viável para estímulo na aprendizagem histórica e educação patrimonial.

\section{Introdução}

Conhecer a história local tornou-se um instrumento importante na construção da identidade de uma sociedade. Logo, a Educação Patrimonial atua de modo preservar o conhecimento histórico de forma educativa, buscando manter a história do patrimônio cultural e visando principalmente uma construção coletiva e espontânea [Florêncio et al. 2014]. Centrada na pluralidade cultural, esta educação adota como compromisso uma proposta de preservação e rememoração do que é significante ao setor educacional no âmbito nacional, regional e municipal [Bittencourt 2009].

A cidade de Icó-Ceará compõe o elenco dos municípios históricos do Brasil, possuindo patrimônios tombados protegidos pelo Instituto do Patrimônio Histórico e Artístico Nacional (IPHAN). Em 2012, Icó tornou obrigatória a disciplina sobre a história do município para todos os alunos do ensino fundamental. Tal inclusão está de acordo com o artigo 26 da Lei de Diretrizes e Bases da Educação Nacional (LDB) que sugere aos currículos do ensino fundamental e médio, em sua parte diversificada, conteúdos relativos às características locais e regionais culturais, buscando promover a divulgação 
VII Congresso Brasileiro de Informática na Educação (CBIE 2018)

Anais dos Workshops do VII Congresso Brasileiro de Informática na Educação (WCBIE 2018)

do acervo patrimonial dos municípios e dos estados [Brasil 1996]. No caso específico da cidade de Icó - Ceará, confirma-se o momento de transformação do espaço vinculado às modificações dos hábitos de uma sociedade contemporânea.

Nesta conjuntura, as transformações históricas e processos sociais estão sendo induzidos pelo paradigma da tecnologia da informação [Castells 2010], por conseguinte, também influenciando no ensino aprendizagem. Para [Guy 2009] a utilização de dispositivos móveis, através do o m-learning, possibilita aos estudantes uma alta mobilidade sem a necessidade de fixação a um ambiente específico. Assim, o objetivo deste trabalho consiste na validação de um aplicativo para dispositivos móveis "HistoryIcó" como instrumento de auxílio à educação patrimonial.

\section{HistoryIcó}

O HistoryIcó é um aplicativo para dispositivos móveis desenvolvido com o intuito de prover funcionalidades que apoiem à manutenção e resgate da educação patrimonial na cidade de Icó-Ceará. De forma técnica, o HistoryIcó foi desenvolvido para smartphones com sistema operacional Android, tendo como principal característica o funcionamento ubíquo, permitindo assim que seja executado em qualquer hora e em praticamente qualquer lugar [Weiser 1991].

Dentre os conteúdos, estão presentes a apresentação de curiosidades, contos e a história de 23 patrimônios da cidade que podem ser visualizadas através de imagens, áudios e vídeos ou por meio da reprodução da história no próprio local, reforçando uma aprendizagem móvel com interatividade social, sensível ao contexto e centrada principalmente no patrimônio cultural e suas características individuais. Nas Figuras 1, 2, 3 e 4 são apresentadas algumas das interfaces do aplicativo e suas funcionalidades.

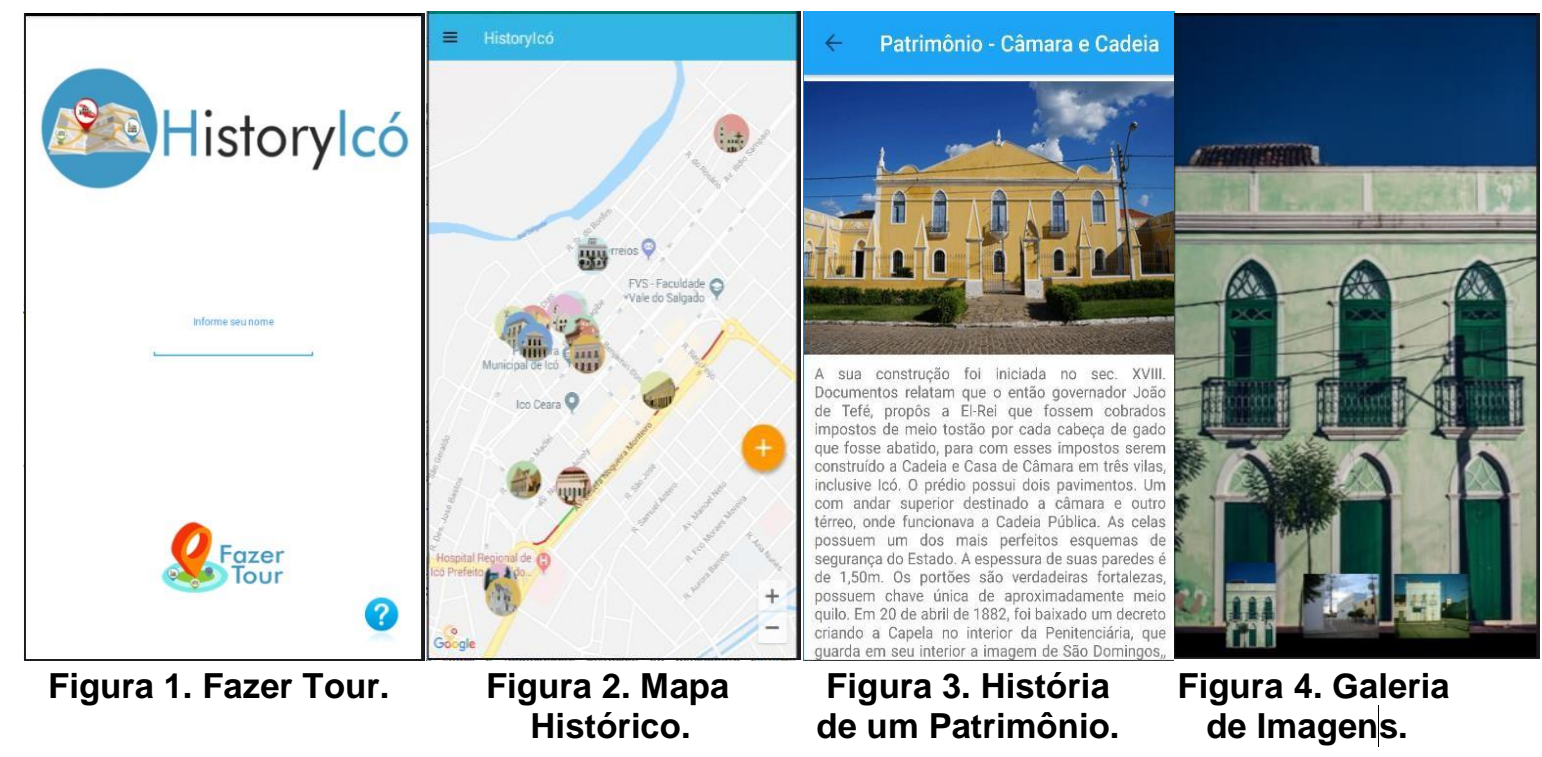

\section{Método}

Como método deste trabalho, o aplicativo HistoryIcó foi utilizado com alunos na disciplina de história do município em uma escola municipal da zona urbana de Icó. Para tal, o público consistiu em uma amostra de 32 alunos com idades entre 10 a 12 anos de ambos os gêneros. 
VII Congresso Brasileiro de Informática na Educação (CBIE 2018)

Anais dos Workshops do VII Congresso Brasileiro de Informática na Educação (WCBIE 2018)

Inicialmente, professores e alunos foram treinados e orientados acerca do funcionamento do aplicativo. Após isso, o aplicativo foi utilizado durante o período de 12 semanas (aproximadamente 3 meses) pelo professor como meio de ensino e fixagem da história do município, concentrando-se especificamente na aprendizagem dos patrimônios, contos e tradições da cidade. Após esta etapa, foram aplicados formulários com questões fechadas baseadas na escala de Likert de 5 pontos para todos os alunos.

\section{Resultados e Discussão}

Ao todo foram realizadas 5 perguntas, onde buscou-se primeiramente identificar a capacidade de uso do HistoryIcó, tendo sido feita a seguinte pergunta: "i) Consegui utilizar o aplicativo de maneira simples e clara não tendo tantas dificuldades no uso". Neste aspecto, 25 dos participantes alegaram concordar totalmente, 3 alegaram concordar parcialmente, 1 outro não concordou nem discordou, mantendo-se neutro e outros 2 discordaram parcialmente e totalmente.

Já na segunda pergunta, visou-se coletar a capacidade de representatividade dos patrimônios, tradições e crenças presentes no aplicativo, onde foi feita a seguinte pergunta: "ii) Por meio do aplicativo pude identificar e conhecer patrimônios históricos da cidade bem como tradições e crenças". Em análise, 29 alunos concordaram totalmente, 1 concordou parcialmente, outro nem concordou nem discordou, e por fim, 1 respondeu que discorda parcialmente. A maioria positiva pode ser justificada pelo fato de que o patrimônio cultural e suas características são fundamentais, pois o aluno pode interagir com os patrimônios e sua história através de um aplicativo móvel interativo [Abreu, de Sousa and Lacerda 2017]

$\mathrm{Na}$ terceira, a pergunta realizada buscou identificar a colaboração do aplicativo para a percepção de significância e importância histórica, sendo: “iii) Considero que com o uso do aplicativo pude perceber de forma mais próxima a importância histórica da minha cidade". 30 participantes responderam que concordam totalmente, 1 outro não concorda nem discorda, e por último 1 outro não concorda parcialmente.

A quarta pergunta consistiu em identificar a correlação entre os conteúdos apresentados no aplicativo e os conteúdos abordados na disciplina de história do município, para tal foi feita a seguinte pergunta: "iv) Os conteúdos vistos no aplicativo me ajudaram na compreensão e assimilação do que era ensinado pelo professor". Onde, 28 concordaram totalmente, 3 concordaram parcialmente e mais 1 nem concordou nem discordou.

A última pergunta foi: "v) De modo geral, usar o aplicativo para reforçar os conteúdos das aulas tornou minha aprendizagem mais atrativa e interessante". Em grande maioria, 31 de 32 participantes concordaram totalmente com a asserção, demonstrando a significância do HistoryIcó aos mesmos. Tal resultado mostra que a capacidade de experiência de vivência próxima patrimônio e da história, faz do HistoryIcó um instrumento de turismo educacional que pode atuar como uma ferramenta de auxílio. Corroborando, [Cardoso and Gattiboni 2015] afirmam que o turismo pedagógico educacional permite um aprendizado em vivência, permitindo assim que haja um aprendizado associado a prática e a teoria no âmbito educacional.

Como forma de apresentar os resultados de maneira quantitativa, a Tabela 1 apresenta os resultados totais das frequências multiplicadas pelo peso, onde, a frequência (f) é igual ao tamanho da amostra (32), e os pesos são obtidos com base em Likert, sendo (Concordo Totalmente $=5$... Discordo Totalmente $=1$ ). 
VII Congresso Brasileiro de Informática na Educação (CBIE 2018)

Anais dos Workshops do VII Congresso Brasileiro de Informática na Educação (WCBIE 2018)

Tabela 1. Frequência x Peso.

\begin{tabular}{|c|c|c|c|c|c|}
\cline { 2 - 6 } \multicolumn{1}{c|}{} & Questão 1 & Questão 2 & Questão 3 & Questão 4 & $\begin{array}{c}\text { Questão } \\
5\end{array}$ \\
\hline$f x P$ & 146 & 154 & 155 & 155 & 158 \\
\hline
\end{tabular}

Como forma de identificar as médias de cada uma das respostas, a seguinte fórmula foi adotada: Totalf $x$ P / 32 (frequência). Os resultados são dispostos no Gráfico 1 apresentando todas as médias das 5 perguntas apresentadas como QST1-QST2 - QST3 QST4 e QST5 respectivamente.

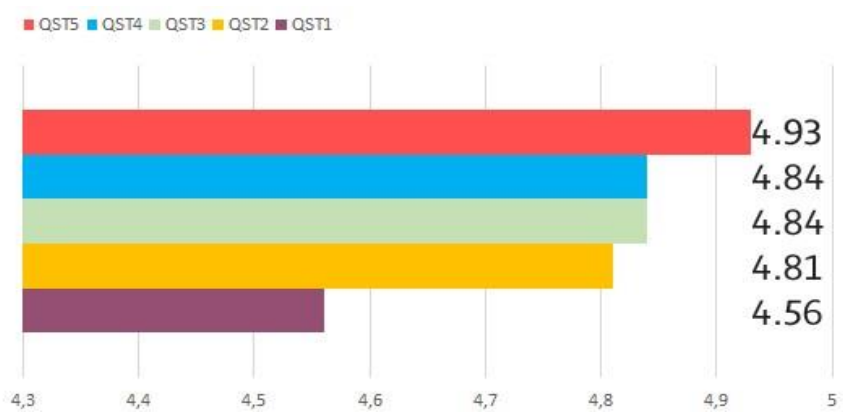

Figura 1. Médias das Respostas.

\section{Conclusão}

Respeitar a história e seu rico passado é uma questão de cidadania, cultura, história, arte e principalmente de identidade. Frente a isto, cada vez mais a história, patrimônios, tradições e crenças necessitam ser preservados na memória dos jovens, futura geração. Assim, ao utilizar um aplicativo como instrumento de apoio à educação patrimonial, os resultados demonstraram que o HistoryIcó apresentou-se como um recurso válido para apoio à aprendizagem do município no contexto da cidade de Icó-Ceará.

\section{Referências}

Abreu, J., de Sousa, J. E. and Lacerda, M. (2017). Um Aplicativo Móvel Para Educação Ambiental. In Simpósio Brasileiro de Informática na Educação-SBIE) (Vol. 28, No. 1, p. 1736).

Bittencourt, C. M. F. (2009). Materiais didáticos: concepções e usos. Ensino de História: fundamentos e métodos. São Paulo: Cortez.

Brasil. (1996). Lei de Diretrizes e Bases da Educação Nacional. Lei número 9394, 20 de dezembro de 1996.

Cardoso H. R and Gattiboni M. D. (2015). Turismo Pedagógico: Uma Alternativa para Integração Curricular. In Professare. 2015 Sep 9;4(1):85-110.

Castells, M., (2010). A era da informação: a sociedade em rede, v. 1. 5. São Paulo: Paz e Terra.

Florêncio, S. R., Clerot, P., Bezerra, J. and Ramassote, R., 2014. Educação Patrimonial: histórico, conceitos e processos. Brasília, DF: Iphan/DAF/Cogedip/Ceduc.

Guy, R. ed. (2009). The evolution of mobile teaching and learning. Informing Science.

Weiser, M. (1991). The Computer for the 21st Century. In Scientific American, [S.1.], v.3, n.265, p.94-104. 